\title{
THE EFFECT OF INTRAVENOUS CORTISOL INJECTIONS ON THE PLASMA CORTISOL CONCENTRATION IN MAN ${ }^{1}$
}

\author{
By JAMES SCHEUER ${ }^{2}$ AND PHILIP K. BONDY \\ (From the Department of Medicine, Yale University School of Medicine, Nerw Haven, Conn.)
}

(Submitted for publication May 24, 1956; accepted October 4, 1956)

Previous workers have shown (1-7) that 17hydroxycorticosteroids disappear rapidly from the plasma after cortisol (hydrocortisone) is injected intravenously. The disappearance rates have not, however, been studied in detail nor have analytical methods been used which would distinguish cortisol from its reduced derivatives. In the present experiments disappearance curves of cortisol have been determined, both after sudden massive injections, and during slow infusions at rates which permitted the establishment of equilibrium at physiological plasma cortisol concentrations. Steroid determinations have been performed by methods which separate cortisol from all other steroids known to be present in human plasma.

\section{MATERIALS AND METHODS}

All subjects were healthy male medical students between the ages of 21 and 25 years, without evidence of serious disease or history of hepatic, renal or endocrinological abnormality. Studies were started between 8:30 and 9:30 a.m. The subjects were ambulatory but otherwise inactive. They were on normal diets throughout the experiment and all understood the nature of the procedure. Five subjects were used in each part and those who participated in Part I were not used in Part II.

Heparinized blood samples were centrifuged immediately upon withdrawal and except in a few cases were extracted the same day. On occasion it was necessary to freeze the plasma for a few days prior to extraction. The plasma samples were analyzed by the method of Bondy, Abelson, Scheuer, Tseu, and Upton $(8,9)$, a brief description of which follows.

Appropriate duplicate quantities of plasma were extracted with chloroform and the extracts chromatographed in the Bush toluene-75 per cent methanol paper chromatography system. Cortisol spots were eluted with ethyl alcohol and the quantity of steroid measured by potassium butoxide fluorometry (8). Small amounts of

1 Supported by Research Grant A-254(C3) from the National Institutes of Arthritis and Metabolic Diseases of the National Institutes of Health, U. S. Public Health Service.

2 This work represents a portion of the material presented in satisfaction of the thesis requirement for the M.D. degree at Yale University School of Medicine.
cortisol-4-C $\mathrm{C}^{14}$ were added to the original plasma sample and the radioactive recovery used to correct for losses during the procedure. The calculated standard deviation between duplicate samples with this method is \pm 7 per cent, and recovery of added cortisol is $100 \pm 14$ per cent.

\section{EXPERIMENTAL PROCEDURE}

Part I: A control blood specimen was drawn and then $100 \mathrm{mg}$. of cortisol (Upjohn) in $150 \mathrm{ml}$. of 6.7 per cent alcohol and 5 per cent glucose in water were injected over a 5-minute period through the same needle. Blood samples were taken at $15,60,150,300$, and 420 minutes from a vein in the opposite arm. In two subjects samples were taken every 15 minutes for the first hour and every 20 minutes for the second hour. The total amount of blood drawn was $320 \mathrm{ml}$.

Part II: After an initial blood sample had been drawn, an infusion of cortisol in $500 \mathrm{ml}$. of 5 per cent glucose (Merck) was injected intravenously through a constant infusion pump at approximately $300 \mu \mathrm{g}$. per minute. Thereafter blood was withdrawn from the opposite arm at $60,165,180,300$, and 480 minutes. After withdrawal of the 180-minute sample the infusion was stopped and the solution run through the pump and needle into a $100-\mathrm{ml}$. volumetric flask for 10 minutes. The flask was then filled to volume with distilled water. An appropriate aliquot was extracted with chloroform three times. The chloroform was evaporated and the residue dissolved in $6 \mathrm{ml}$. absolute ethyl alcohol and read on a Beckman Model DU spectrophotometer at a wave length of $242 \mathrm{~m} \mu$ to determine accurately the amount of cortisol infused over a 10-minute period. The total amount of blood drawn was $360 \mathrm{ml}$.

Urine analyses were not performed because the portion of injected cortisol excreted unchanged by the kidney is very small (5).

\section{CALCULATIONS}

Part I: At the time of the first post-infusion sample it was assumed that the adrenal gland was no longer secreting cortisol and that the amount of endogenous cortisol present was relatively very small so that the plasma level was almost totally due to exogenous cortisol. If the disappearance of the steroid from the plasma is proportional to the concentration (2), it is represented by the equation :

$$
-\frac{d c}{d t}=K c
$$


where $\mathrm{c}$ is the concentration in the theoretical volume of distribution, $v$. It is assumed that $\mathrm{c}$ is constant throughout $\mathrm{v}$ (see below). By integrating:

$$
\mathrm{c}=\mathrm{C}_{\mathrm{oe}} \mathrm{e}^{-\mathrm{kt}}
$$

where $\mathrm{C}_{0}$ is the concentration at time zero.

Part II: The same assumptions were made regarding the endogenous cortisol as in Part I. Since the cortisol was being added to the system at a constant rate, the change of concentration assuming no loss would be:

$$
\frac{\mathrm{dc}}{\mathrm{dt}}=\frac{\mathrm{r}}{\mathrm{v}}
$$

where $r$ is rate of infusion. When the rate of disappearance of the steroid is taken into account (Equation 1) net increase in concentration may be represented as :

$$
\frac{\mathrm{dc}}{\mathrm{dt}}=\frac{\mathrm{r}}{\mathrm{v}}-\mathbf{k c}
$$

If the concentration of cortisol was zero at time zero, then :

$$
c=\frac{r}{k v}\left(1-e^{-k t}\right)
$$

When $t=\infty, c$ reaches an asymptote:

$$
\mathrm{c}=\frac{\mathrm{r}}{\mathrm{kv}}
$$

$r$ is a known constant and the values for $c$ are known at different times. Substituting these values in Equation $5, \mathrm{v}$ and $\mathrm{k}$, can be derived. The descending curve is analyzed by Equation 2 .

The elimination of endogenous cortisol has been calculated in Parts I and II from Equation 2, assuming that disappearance of endogenous hormone proceeded at the same rate as exogenous cortisol when at equilibrium (7). By subtracting the calculated endogenous curves from the total, one obtains an approximation of the exogenous curves (Figures 1, 2, and 3 ).

\section{RESULTS}

Table I represents the levels of cortisol obtained after the acute injection of this substance. The concentrations differ widely about the mean, but each falls on a smooth curve. A graph of the

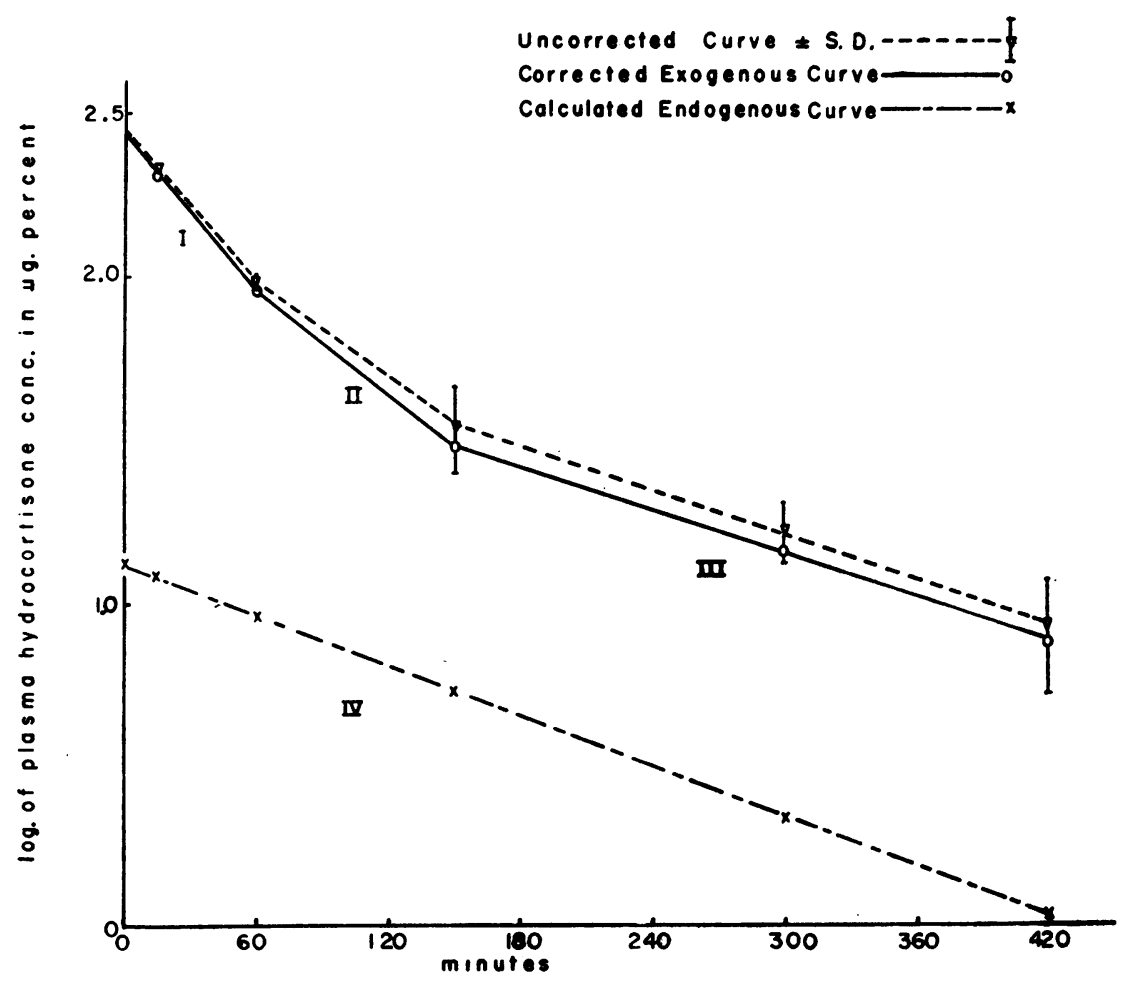

Fig. 1. Mean Concentration of Plasma Cortisol after the Rapid INJECTION OF 100 Mg. OF CORTISOL

The equations for the various curves are as follows:
I. $c=264 \mathrm{e}^{-0.0180 \mathrm{t}}$
$\mathbf{t}_{\mathbf{i}}=37$ minutes
II. $c=88.1 \mathrm{e}^{-0.0120 \mathrm{t}}$
$t_{\hat{j}}=58$ minutes
III. $c=29.5 \mathrm{e}^{-.00614 \mathrm{t}}$
$t_{\xi}=138$ minutes
IV. $c=13.1 \mathrm{e}^{-0.00514 t}$ 


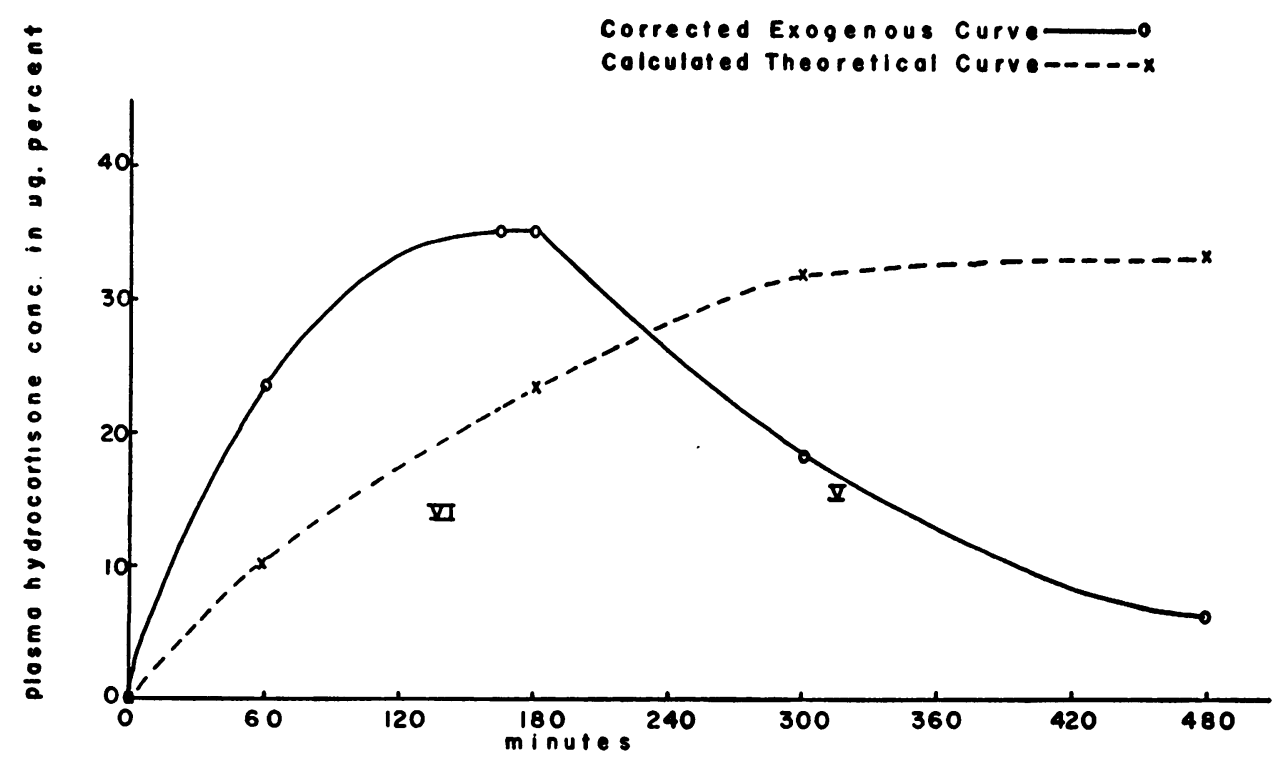

Fig. 2. Mean Concentration of Plasma Cortisol during Continuous intravenous Injection of Cortisol at a Rate of $301 \mu \mathrm{g}$. Per Minute (Solid Line) and the Curve Which Would have Been Obtained if the Rate Constant and Volume of Distribution Had Been Constant Throughout the Experiment

The infusion was stopped at 180 minutes. The equations for the curves are as follows:

$$
\begin{aligned}
& \text { V. } \quad c=35.2 \mathrm{e}^{-0.00568 \mathrm{t}} \quad \mathrm{t}_{\mathrm{j}}=124 \text { minutes } \\
& \text { VI. } \quad c=\frac{301}{1550(.00568)}\left(1-\mathrm{e}^{-0.00568 \mathrm{t}}\right)
\end{aligned}
$$

mean values is shown in Figure 1. During the first 150 minutes the rate of disappearance from the plasma decelerates fairly evenly so that the logarithm of the concentration forms a concave curve when plotted against time. This curve can be represented by two arbitrary straight lines which approximate the average rates of disappearance during those periods. Thus, during the first 60 minutes there is a rapid disappearance from the plasma at an average rate of 1.84 per cent per minute. Over the next 90 minutes the disappearance averages 1.20 per cent per minute. For the next 230 minutes the disappearance rate remains constant at 0.51 per cent per minute with a mean half-life of 138 minutes and a range among our subjects of 58 to 161 minutes.

Frequent samples were taken during the first 150 minutes in two subjects. The results are shown in Table II. Because of the very high levels of exogenous steroid during this early part of the curve, the endogenous levels represent a negligible portion of the plasma concentration and may be ignored. During this time there is a rapid fall, especially in subject JS where the level seems to fall to low values and then rebound upward to approach the mean curve. This early fall is much larger than the experimental error, since the standard deviation of the analytical method was only \pm 8.5 per cent. The number of subjects is too small for general conclusions; however, the data demonstrate the rapidity of fall and the variability of the rate of disappearance immediately after a single, large injection of cortisol.

If one assumes that the plasma volume is 4 per cent of body weight, in these experiments 94.0 per cent of the administered dose had disappeared from the plasma after 15 minutes, 97.4 per cent at the end of 60 minutes, and 99.1 per cent after 150 minutes. In these instances the plasma cortisol level fell below the initial endogenous concentration 300 to 420 minutes after the steroid injection.

Table III represents the results obtained with the constant infusion in Part II. Here, as in Part $\mathrm{I}$, there is a wide individual variation from the mean. The values at 165 minutes and $180 \mathrm{~min}$ utes are so similar for any given subject that it 


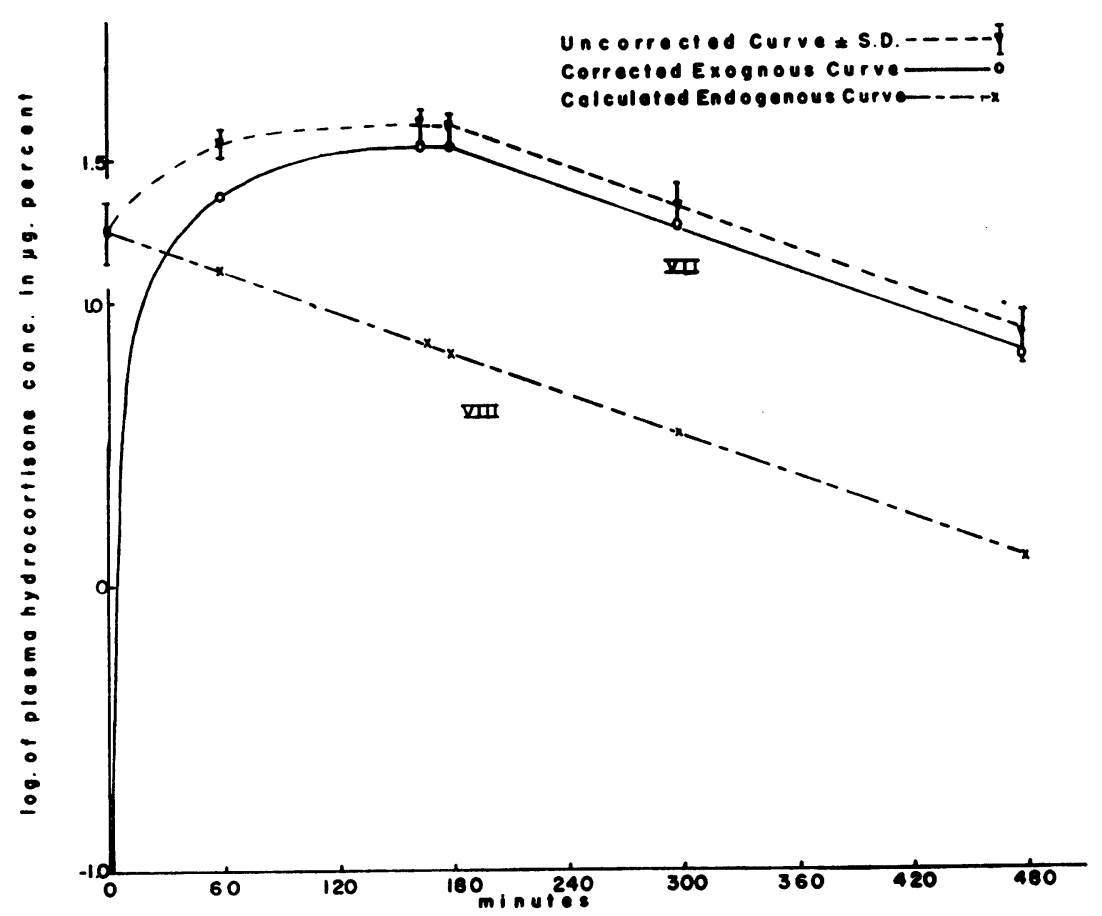

Fig. 3. Mean Concentration of Plasma Cortisol during Continuous Intravenous Injection of Cortisol at a Rate of $301 \mu \mathrm{g}$. PER Minute

Curve VII is the same as curve V, Figure 2, with the ordinate expressed as the logarithm of plasma cortisol concentration. The equation for curve VIII is as follows:

$$
\text { VIII. } c=17.5 \mathrm{e}^{-0.00568 \mathrm{t}}
$$

has been thought valid to average them and consider that the curve has reached its asymptote during this period. The equilibrium concentrations range from 25.8 to $66.9 \mu \mathrm{g}$. per cent. During the infusion the rate of disappearance of cortisol decreases constantly, leveling off during the final 15 minutes toward a half-life of 172 minutes. During this 15-minute period the theoretical volume of distribution ( $v$ in Equation 5) averages 116 per cent of body weight. The value of $v$ may also be calculated from Equation 6, using the $k$ value obtained from the falling limb of the curve, and $c$

TABLE I

Plasma cortisol levels after a single intravenous injection of cortisol-Part I

\begin{tabular}{|c|c|c|c|c|c|c|c|}
\hline \multirow[b]{2}{*}{ Subject } & \multirow[b]{2}{*}{$\begin{array}{c}\text { Weight } \\
\text { kg. }\end{array}$} & \multicolumn{6}{|c|}{ Time in minutes } \\
\hline & & $\mu \mathrm{0} . / 100 \mathrm{ml}$. & $\mu 8 . / 100 \mathrm{ml}$. & $\mu 8 . / 100 \mathrm{ml}$. & $\mu g . / 1500 \mathrm{ml}$ & $\mu g . / 100 \mathrm{mb}$. & $\stackrel{420}{\mu g . / 100 \mathrm{ml} .}$ \\
\hline $\begin{array}{l}\text { CH } \\
\text { AB } \\
\text { JC } \\
\text { JS } \\
\text { AH }\end{array}$ & $\begin{array}{l}92.9 \\
75.0 \\
71.8 \\
61.3 \\
72.8\end{array}$ & $\begin{array}{r}10.0 \\
9.4 \\
4.5 \\
22.5 \\
18.9\end{array}$ & $\begin{array}{l}140.0 \\
205.0 \\
179.0 \\
227.0 \\
314.0\end{array}$ & $\begin{array}{r}84.0 \\
73.8 \\
63.0 \\
70.9 \\
197.0\end{array}$ & $\begin{array}{l}14.5 \\
31.1 \\
37.5 \\
49.5 \\
39.0\end{array}$ & $\begin{array}{r}2.5 \\
15.6 \\
19.5 \\
25.0 \\
21.0\end{array}$ & $\begin{array}{r}8.2 \\
4.0 \\
12.0 \\
10.0 \\
8.7\end{array}$ \\
\hline Mean $\pm S D$ & 74.8 & $13.1 \pm 3.2$ & $213.0 \pm 9.4$ & $97.7 \pm 6.5$ & $35.5 \pm 10.6$ & $16.7 \pm 3.5$ & $8.6 \pm 3.9$ \\
\hline $\begin{array}{l}\text { Calculated mean } \\
\text { endogenous levels }\end{array}$ & & 13.1 & 12.1 & 9.6 & 6.0 & 2.8 & 1.5 \\
\hline $\begin{array}{l}\text { Calculated mean } \\
\text { exogenous levels } \\
\text { (corrected for } \\
\text { endogenous decay) }\end{array}$ & & 0 & 201.0 & 88.1 & 29.5 & 13.9 & 7.1 \\
\hline
\end{tabular}


TABLE II

Plasma cortisol levels during the first 150 minutes after a single intravenous injection-Part I

\begin{tabular}{|c|c|c|c|c|c|c|c|c|}
\hline \multirow[b]{2}{*}{ Subject } & \multicolumn{8}{|c|}{ Time in minutes } \\
\hline & $\stackrel{15}{\mu g . / 100 ~ m b .}$ & $\begin{array}{c}30 \\
\mu g . / 100 \mathrm{ml} .\end{array}$ & $\stackrel{45}{\mu g . / 100 \mathrm{ml} .}$ & $\stackrel{60}{\mu g . / 100 \mathrm{ml} .}$ & $\stackrel{80}{\mu g . / 100 \mathrm{ml} .}$ & $\stackrel{100}{\mu g . / 100 \mathrm{ml} .}$ & $\stackrel{120}{\mu g . / 100 ~ m l . ~}$ & $\begin{array}{c}150 \\
\mu g . / 100 \mathrm{ml} .\end{array}$ \\
\hline$\underset{A H}{\mathbf{A H}}$ & $\begin{array}{l}227.0 \\
314.0\end{array}$ & $\begin{array}{l}136.0 \\
219.0\end{array}$ & $\begin{array}{r}42.2 \\
188.0\end{array}$ & $\begin{array}{r}70.9 \\
197.0\end{array}$ & $\begin{array}{r}42.2 \\
136.8\end{array}$ & $\begin{array}{l}83.3 \\
82.1\end{array}$ & $\begin{array}{l}\mathbf{5 5 . 5} \\
\mathbf{5 6 . 0}\end{array}$ & $\begin{array}{l}49.5 \\
39.0\end{array}$ \\
\hline
\end{tabular}

obtained during the last 15 minutes of the infusion. By this calculation the mean volume $v$ is 186 per cent of body weight. The lower value of $v$, in the first calculation arises from the fact that $k$ on the ascending portion of the curve is larger than during the descending portion, suggesting that true equilibrium may not have been reached at 180 minutes. Figure 2 shows the calculated mean curve plotted on linear graph paper and the theoretical curve one would obtain if $v$ and $k$ were constant throughout and equal to the 180-minute values. Figure 3 shows the mean curve on semilogarithmic paper. In Part II, as in Part I, after equilibrium has been reached cortisol disappears from the blood at a rate of 0.57 per cent per minute with a half-life of 124 minutes and an individual range of 93.6 to 141 minutes. During the infusion, at 60 minutes 96.7 per cent, and at 180 minutes 97.9 per cent, of the administered cortisol had disappeared from the plasma.

Pre-infusion levels in all subjects in Part II, except TT, are above the normal range. At a later date samples were drawn from these subjects and found to be within normal range. At the end of Part II, as in Part I, there is a dip in the plasma cortisol level below the initial endogenous level.

\section{DISCUSSION}

In these experiments, after a period of equilibration cortisol disappears from the blood stream at a constant rate, with an average half-life of about 130 minutes. This confirms the observation by Eik-Nes, Sandberg, Nelson, Tyler, and Samuels (1) that the elevated blood 17-hydroxycorticosteroids induced by ACTH decreased at a rate proportional to the concentration. Similarly, Brown, Willardson, Samuels, and Tyler (3) gave intravenous cortisol over a 30-minute period and found that after 60 minutes the plasma 17-hydroxycorticosteroid concentration fell exponentially. EikNes, Sandberg, Tyler, and Samuels (2) published a mean curve from which a half-life of about 120 minutes can be calculated. Done, Ely, Olsen, and Kelley (4) found that the half-life of 17-hydroxy-

TABLE III

Plasma cortisol levels during and after constant infusion of cortisol-Part II

\begin{tabular}{|c|c|c|c|c|c|c|c|c|}
\hline \multirow[b]{2}{*}{ Subject } & \multirow[b]{2}{*}{$\underset{k \text { kg. }}{\text { Weight }}$} & \multirow[b]{2}{*}{$\begin{array}{l}\text { Inf. rate } \\
\mu g . / \min .\end{array}$} & \multicolumn{6}{|c|}{ Time in minutes } \\
\hline & & & $\stackrel{0}{0} \mathrm{mg} .100 \mathrm{ml}$. & $\stackrel{60}{\mu g . / 100 \mathrm{ml} .}$ & $\mu g . / 100 \mathrm{ml}$. & $\mu g . / 100 \mathrm{ml}$. & $\stackrel{300}{\mu g . / 100 \mathrm{ml} .}$ & $\mu \mathrm{Hg} / 100 \mathrm{ml}$. \\
\hline $\begin{array}{l}\text { JK } \\
\text { GE } \\
\text { RW } \\
\text { AH } \\
\text { TT }\end{array}$ & $\begin{array}{l}74.0 \\
77.6 \\
77.3 \\
88.7 \\
95.5\end{array}$ & $\begin{array}{l}327 \\
371 \\
231 \\
378 \\
227\end{array}$ & $\begin{array}{r}22.9 \\
21.6 \\
21.0 \\
15.0 \\
7.2\end{array}$ & $\begin{array}{l}62.2 \\
37.2 \\
33.3 \\
24.0 \\
23.6\end{array}$ & $\begin{array}{l}69.5 \\
38.8 \\
45.0 \\
25.8^{*} \\
36.2\end{array}$ & $\begin{array}{l}64.3 \\
37.8 \\
49.0 \\
25.8 \\
28.8\end{array}$ & $\begin{array}{l}33.7 \\
18.4 \\
20.8 \\
20.0 \\
15.2\end{array}$ & $\begin{array}{r}15.4 \\
4.3 \\
7.9 \\
4.0 \\
5.5\end{array}$ \\
\hline Mean \pm SD & 83.0 & 301 & $17.5 \pm 4.2$ & $36.1 \pm 4.2$ & $43.1 \pm 6.3$ & $41.1 \pm 4.5$ & $21.6 \pm 3.8$ & $7.4 \pm 1.6$ \\
\hline \multicolumn{3}{|c|}{$\begin{array}{l}\text { Calculated mean } \\
\text { endogenous levels }\end{array}$} & 17.5 & 12.6 & 7.0 & 6.5 & 3.3 & 1.2 \\
\hline \multicolumn{3}{|c|}{$\begin{array}{l}\text { Calculated mean } \\
\text { exogenous levels } \\
\text { (corrected for } \\
\text { endogenous decay) }\end{array}$} & 0 & 23.5 & \multicolumn{2}{|c|}{$35.2 \dagger$} & 18.3 & 6.2 \\
\hline
\end{tabular}

* Because of error in analysis of the 165 -minute sample there was no value obtained. The 180 -minute value is used in order to preserve the mode of the average curve.

$\dagger$ The mean of the 165- and 180-minute values. 
corticosteroids after intravenous injection of cortisol in normal subjects ranged from 60 to 133 minutes, with an average of 90 minutes. Sayers and his associates (5) observed disappearance of cortisol at a rate proportional to concentration, with half-lives of 78 to 138 minutes in one normal and two Addisonian patients. Peterson, Wyngaarden, Guerra, Brodie, and Bunim (6) found a half-life in 20 normal subjects of $114 \pm 6.5 \mathrm{~min}-$ utes, with a range of 90 to 130 minutes. This constant rate is due mainly to the activity of the liver, since Tomizawa, Narahara, Gibbons, and Williams (10) showed that hepatectomized rats did not metabolize cortisol, and Brown, Willardson, Samuels, and Tyler (3) found that in patients with liver disease the disappearance rate of 17 hydroxycorticosteroids was slowed proportional to the retention of bromosulfaphthalein. Peterson, Wyngaarden, Guerra, Brodie, and Bunim (6) also found increased half-lives in all their patients with liver disease.

The rapid initial removal of cortisol from the blood stream, described by others $(3,7)$, has been confirmed in the present experiments. Thus, Brown, Willardson, Samuels, and Tyler (3) found less than 5 per cent free 17 -hydroxycorticosteroids in the plasma 60 minutes after intravenous administration, and Hellman and his associates (7) found only 13 per cent of $\mathrm{C}^{14}$-labeled cortisol present in the plasma 15 minutes after infusion. In most of the previous experiments, the analytical methods used were somewhat nonspecific, since dihydrocortisol and tetrahydrocortisol would have been included in the "17-hydroxycorticosteroid" fraction if present in free form. Apparently negligible amounts of these substances are present, however, since the results obtained with a highly specific analytical technique in the present experiments are similar to those obtained with somewhat less specific methods.

In all of the previous studies, plasma concentrations were determined only 60 minutes or more after the steroid had been injected. If the data presented by Eik-Nes, Sandberg, Tyler, and Samuels (2) for individual curves are plotted on semi-logarithmic paper, the concentration in each case falls more rapidly between the first and second hour than during the remainder of the time.

In the present experiments the disappearance curve was not exponential for the first $150 \mathrm{~min}$ - utes after the single intravenous injection of cortisol, but showed a steadily decreasing value for $k$. During the constant injection experiments also either $k$ decreased or $v$ increased, or both, until equilibrium was reached. This suggests that cortisol leaves the plasma more rapidly early in the experiment than it does after several hours. If the late exponential disappearance rate is constant during the early part of the experiments, which seems a reasonable assumption, then the accelerated rate observed in the initial hours, which accounts for about 48 per cent of the total disappearance as estimated from the areas under the curves, must reflect the presence of additional disposal systems besides the one which controls the rate of disappearance at equilibrium. Since accelerated cortisol disposal occurred early during the constant infusion experiments, the initial rapid rate of disappearance cannot be merely the result of elevated plasma cortisol concentration, or of delay in mixing throughout the volume of distribution. The loss of steroid directly by renal excretion can be ignored since the quantities of unmetabolized cortisol entering the urine are negligible (5). The temporary rapid disappearance rates early in both experiments therefore presumably represent the rapid entry of cortisol into body compartments other than the plasma (i.e., a period of "equilibration" [10]). Since extracellular water contains no more cortisol than the plasma (11-16), the steroid must enter the cells. Levin, Daughaday, and Bremer have suggested that this equilibration is in part a result of binding of cortisol to tissue proteins (12), since many proteins can form nondialyzable complexes with steroids (13). In any case, the present data show that calculation of a single theoretical volume of distribution, $v$, is unwarranted since it is based on the assumption that the concentration of cortisol is the same throughout the entire volume of distribution as it is in the plasma. Since $v$ proves to be larger than the total body volume both in these experiments and in those of others $(6,10)$, the concentration of cortisol in sites of binding outside of the plasma appears to be much higher than in the plasma.

The low values for cortisol found at the end of the experiment may be due to the suppression of ACTH by exogenous cortisol with a lag period after most of the exogenous cortisol has been 
metabolized, leaving an adrenal that has had no stimulation for a few hours.

There must be many unrecognized variables which act upon the distribution and disappearance of cortisol to account for the wide range of individual values. Pre-injection steroid concentrations were frequently elevated in subjects later proved to be normal, suggesting that the test situation itself may alter in some way either the rate of endogenous secretion or rate of disposal of the hormone.

\section{SUMMARY}

1. One hundred mg. of cortisol were injected intravenously in 5 minutes into healthy subjects and the disappearance of the steroid from the plasma was followed. The rate of removal, which was very rapid at first, gradually decreased to about one-third of the original rate at 150 minutes, after which it remained constant with a mean half-life for plasma cortisol of 138 minutes.

2. In a second set of experiments, a constant intravenous infusion of approximately $300 \mu \mathrm{g}$. per minute was given. At 180 minutes equilibrium was reached when the amount leaving the plasma equalled the amount entering. The post-infusion curve was plotted and a mean half-life of 124 minutes was found. The volume of distribution of cortisol when the plasma concentration was at equilibrium was greater than the body weight, indicating that this "volume of distribution" has no real meaning.

3. Plasma cortisol concentrations a few hours after the infusion were lower than those found prior to the injection.

4. The results suggest that cortisol may leave the plasma in two general ways: via a reversible system in which the steroid is bound in high concentrations to tissue proteins; and an irreversible system whereby cortisol is permanently removed from the plasma. The early part of the disappearance curve is greatly influenced by the reversible binding of the steroid, whereas the later portion of the curve reflects a first-order metabolic process, presumably occurring chiefly in the liver.

\section{REFERENCES}

1. Eik-Nes, K., Sandberg, A. A., Nelson, D. H., Tyler, F. H., and Samuels, L. T., Changes in plasma levels of 17-hydroxycorticosteroids during the intravenous administration of ACTH. I. A test of adrenocortical capacity in the human. J. Clin. Invest., 1954, 33, 1502.

2. Eik-Nes, K., Sandberg, A. A., Tyler, F. H., and Samuels, L. T., Plasma levels of 17-hydroxycorticosteroids following the administration of adrenal steroids. Acta Endocrinol., 1955, 18, 244.

3. Brown, H., Willardson, D. G., Samuels, L. T., and Tyler, F. H., 17-hydroxycorticosteroid metabolism in liver disease. J. Clin. Invest., 1954, 33, 1524.

4. Done, A. K., Ely, R. S., Olsen, L. J., and Kelley, V. C., The in vivo half-life of exogenous hydrocortisone in patients with rheumatic fever. Metabolism, 1955, 4, 416.

5. Sayers, G., Glenn, E. M., Sydnor, K. L., Lipscomb, M., Sweat, M. L., Kelly, L. W., Jr., Levy, R. P., and Jefferies, W. McK., Plasma and urinary steroids after hydrocortisone infusion. J. Clin. Invest., $1955,34,1600$.

6. Peterson, R. E., Wyngaarden, J. B., Guerra, S. L., Brodie, B. B., and Bunim, J. J., The physiological disposition and metabolic fate of hydrocortisone in man . J. Clin. Invest., 1955, 34, 1779.

7. Hellman, L., Bradlow, H. L., Adesman, J., Fukushima, D. K., Kulp, J. L., and Gallagher, T. F., The fate of hydrocortisone-4-C $\mathrm{C}^{\mathbf{1 4}}$ in man. J. Clin. Invest., 1954, 33, 1106.

8. Abelson, D., and Bondy, P. K., Fluorometric determination of $\Delta^{4}$-3-ketosteroids. Arch. Biochem. \& Biophys., 1955, 57, 208.

9. Bondy, P. K., Abelson, D., Scheuer, J., Tseu, T. K. L., and Upton, G. V., J. Biol. Chem., In press.

10. Tomizawa, H. H., Narahara, H. T., Gibbons, C. A., and Williams, R. H., A metabolic study of hydrocortisone in rats. Proc. Soc. Exper. Biol. \& Med., 1954, 85, 51.

11. Bradlow, H. L., Dobriner, K., and Gallagher, T. F., The fate of cortisone-T in mice. Endocrinol., 1954, 54, 343.

12. Levin, M. E., Daughaday, W. H., and Bremer, R., Tissue binding of hydrocortisone. J. Lab. \& Clin. Med., 1955, 45, 833.

13. Eik-Nes, K., Schellman, J. A., Lumry, R., and Samuels, L. T., The binding of steroids to protein. I. Solubility determinations. J. Biol. Chem., 1954, 206, 411.

14. Sandberg, A. A., Eik-Nes, K., Nelson, D. H., and Tyler, F. H., Levels of 17-hydroxycorticosteroids in body fluids. J. Lab. \& Clin. Med., 1954, 43, 874.

15. Baron, D. N., and Abelson, D., Cortisone and hydrocortisone in cerebrospinal fluid. Nature, 1954, 173, 174.

16. Cope, C. L., Hurlock, B., and Sewell, C., The distribution of adrenal cortical hormone in some body fluids. Clin. Sc., 1955, 14, 25. 